\title{
1. What I set out to study and why
}

This book is a reconstruction of my journey to understand entrepreneurship as a form of expertise. The day I officially began writing the first edition of this book - June 21, 2004 - was, quite by chance, the day SpaceShipOne made history as the first successful, privately funded, manned commercial space flight. On that day, under the command of test pilot Mike Melvill, SpaceShipOne reached a record-breaking altitude of 328,491 feet (approximately 62 miles or $100 \mathrm{~km}$ ), making Melvill the first civilian to fly a spaceship out of the atmosphere and the first private pilot to earn astronaut wings. SpaceShipOne embodies elements of effectual entrepreneurship.

The story of SpaceShipOne ${ }^{1}$ is tied up with the story of its designer, Burt Rutan. Rutan built his first flying model at age 10. His father was a dentist who teamed up with four other pilots to buy his own plane, and his brother, Dick Rutan was a decorated Air Force pilot who served in Vietnam. Rutan earned a degree in aeronautics from California Polytechnic University in 1965, joined the Air Force testing new airplanes, and in 1972 became director of Bede Aircraft's test center in Kansas. In 1974, he moved his family into the Mojave desert and went into business for himself. His first venture, Rutan Aircraft Factory, developed light aircraft and served the home-built plane market by developing and selling plans. He formed Scaled Composites in 1982 to develop proof-of-concept prototype aircraft for a variety of customers including Boeing and the department of defense. Rutan has over 48 original designs in his portfolio. For example, he designed the Voyager aircraft that flew around the world without refueling in 1986.

In August 2002, the White Knight, a spaceship carrier plane designed by Burt Rutan took to the air. After that, a series of 56 step-by-step flights were undertaken, culminating in the historic moment on June 21, 2004. And in October 2004, SpaceShipOne won the Ansari X-prize. The terms of the international competition for the $\mathrm{X}$-prize included launching three passengers into sub-orbital space in a reusable aircraft twice within a 14-day period.

Rutan's comrade in arms on this venture was Paul Allen, co-founder of Microsoft, who came on board the enterprise as early as March 2001. Since the founding of Microsoft in 1975, Allen had been involved in its research and new product development till 1983. After that he became both investor and philanthropist in a variety of science- and space-related projects - a strong proponent of private non-governmental funding for space programs. For 
example, he funded the construction of the first and second phases of a unique, multiple-use radio telescope array for SETI. The SETI Institute is a leading astrobiology institution with the mission of exploring the origin, nature and prevalence of life in the universe. As part of its duties, the telescope array he funded searches for possible signals from technologically advanced civilizations elsewhere in the galaxy.

Three months after the historic flight on June 21, Sir Richard Branson, founder of Virgin Group announced an agreement with Mojave Aerospace Ventures (MAV) to develop the world's first privately funded spaceships that will carry commercial passengers on space flights. MAV is Paul Allen's company that owns the technology embodied in SpaceShipOne, which in turn was designed by Burt Rutan and built by his company, Scaled Composites. Branson has formed a new company called Virgin Galactic with a view to kick-starting the space tourism industry by 2007. Virgin Galactic's business plan calls for 3,000 astronauts and a ticket price under \$200 K (including three training days) per passenger.

Commenting on the announcement, Virgin Galactic Founder Sir Richard Branson (2004) said:

We've always had a dream of developing a space tourism business and Paul Allen's vision, combined with Burt Rutan's technological brilliance, have brought that dream a step closer to reality. The deals with both their companies, being announced today, are just the start of what we believe will be a new era in the history of mankind, making the affordable exploration of space by human beings real. We hope to create thousands of astronauts over the next few years and bring alive their dream of seeing the majestic beauty of our planet from above, the stars in all their glory and the amazing sensation of weightlessness. The development will also allow every country in the world to have their own astronauts rather than the privileged few.

As I begin writing this second edition, here is the latest news on progress in the space tourism industry in general and Virgin Galactic in particular:

'Virgin Galactic's Stock could Soar $726 \%$, Morgan Stanley says', by Millie Dent, CNN Business. Updated 12:17 PM ET, Mon December 9, 2019

Virgin Galactic's stock is soaring after an analyst said its space planes could one day disrupt the air travel industry, potentially raking in nearly a trillion dollars a year in sales. The spaceflight's company stock surged 12\% Monday after Morgan Stanley released a report predicting Virgin Galactic's (SPCE) shares could rise as high as $\$ 60$ over the coming years if the company successfully executes its business goals. The stock was sitting just below $\$ 8$ before the report was released.

Galactic wants to transition from a space tourism company (it has still yet to fly any civilians into space, but it plans to soon) into a travel company. It intends to accomplish that by building space planes that send passengers on ultra-fast flights around the world. 'A viable space tourism business is what you pay for today,' 
Morgan Stanley analyst Adam Jonas wrote in a note to investors. 'But a chance to disrupt the multi-trillion-dollar airline [total addressable market] is what is really likely to drive the upside.'

The entire story is almost too paradigmatic of the entrepreneurial spirit. The characters are larger than life, straight out of an Horatio Alger myth: Burt Rutan, the brilliant designer of the craft; Michael Melvill and Brian Binnie, the dare-devil pilots; Paul Allen, billionaire sponsor of the enterprise; and of course, the swashbuckling Sir Richard Branson.

On the one hand, it is easy to make shining exemplars of such stories. On the other hand, it is equally easy to write them off as outliers. This book is an attempt to avoid taking either stance toward successful entrepreneurship. It is also an attempt to raise and examine questions that are different than, yet consistent with, issues dominating scholarly discussions of entrepreneurship today.

For example:

- How did Burt Rutan, a graduate of California Polytechnic State University, make the decision to leave a well-paying job at Bede Aircraft in 1974 to strike out on his own and start Rutan Aircraft Factory? What were the antecedents, triggers and processes that brought him to that decision? What other options, if any, did he consider at the point of that decision and what criteria did he use to choose among them?

- How did the characters in the story meet one another? Who, if anyone, introduced them? What led each one to commit to the venture? There are mentions of the venture being staffed by 'volunteers'. How many of these were selected by the stakeholders already on board and how many self-selected and how did the network grow?

- Several key stakeholders have outlined their own goals and those of the venture at various points in time. These narratives are not consistent. Yet together they made SpaceShipOne fly. How clear or ambiguous were the individual goals and aspirations, and how were these woven together into the vision that came to exist? How did the vision get embodied in particular project targets over time?

- What is the role of contingency, as opposed to luck, in all of this?

The questions listed above speak to the micro-foundations of several extant theories of entrepreneurship. They are not about testing larger theories such as those based on technological evolution or industrial organization. They seek to understand instead how stakeholders act, react and interact; how and why these verbs matter; and what they imply about received wisdom. They ask in particular: 
To what extent do actual entrepreneurial actions, reactions and interactions support or challenge the behavioral (micro) assumptions of received theories at the more macro levels?

For example, to what extent do entrepreneurs use predictive as opposed to other types of information to achieve desired outcomes? The design of SpaceShipOne's control system offers an intriguing answer as well as raises new questions. As Brian Binnie, the pilot who made the second flight to win the X-prize, described it:

Unlike NASA's computer-driven space shuttle, SpaceShipOne consists of a simple stick and rudder control system. If somebody had told me when I was in graduate school, 'Brian, in 35 years you'll get a chance to fly the first commercial spacecraft with no computers,' I'd have said, 'You['d] be wrong. People are not going to be that naive.' (Royce Carlton Inc., 2004)

Ed Bradley's description of the design decision during his 60 Minutes piece on SpaceShipOne is rather telling, 'Success is in the hands of the pilot.' And when asked about the craft going into a series of unexpected rolls during the September flight, the pilot, Michael Melvill replied: 'I'm very confident when I'm flying a plane. When I've got the controls in my hand, I always believed I can fix this, no matter how bad it gets.'

Why leave it to the pilot to handle the unexpected, when cheap computing beyond the dreams of the Apollo astronauts is readily available? If control is the key, what does relying on a pilot as opposed to a computer buy us? This design decision serves as a peculiarly apt metaphor for explicating the concept of non-predictive control, which constitutes an important element of the logic of effectuation.

\subsection{CONNECTIONS WITH OTHER THEORETICAL PERSPECTIVES IN ENTREPRENEURSHIP}

Before we get into the details of effectuation, let us consider other theoretical perspectives that have dominated entrepreneurship research and apply them to the SpaceShipOne story.

\subsubsection{The Entrepreneur and her Personality}

For most psychologists looking at the SpaceShipOne story, key questions would revolve around the personality of Burt Rutan and/or the heuristics and biases he is prone to in his decision making. McClelland (1967) for example, would argue that Rutan has a high need for achievement; more recent psy- 
chologists might hypothesize that he has high self-efficacy or high locus of control (Chen et al., 1998); and researchers in entrepreneurial cognition might predict that he suffers from overconfidence bias (Busenitz and Barney, 1997; Camerer and Lovallo, 1999) or that he has a larger than average Adversity Quotient (Markman et al., 2005); others might postulate the necessity of an entrepreneurial mindset (McGrath and MacMillan, 2000).

Effectuation offers an important challenge to this view by showing that while such hypotheses are both interesting and important, they comprise at best a very slim verse in the voluptuous saga of SpaceShipOne. Individual studies find strong relationships between particular psychological variables and particular subsets of entrepreneurs. Subsequently, other studies find relationships in the opposite direction. For example, a few studies have recently revived interest in the role of the Big Five personality traits (Zhao and Seibert, 2006). However, a set of meta-analyses seeking to relate these to entrepreneurial intentions and performance found rather modest effects with risk taking not related to performance (Zhao et al., 2010). Yet another study (Brandstätter, 2011) also examined several meta-analyses of these traits and concluded that the effect sizes were mostly small. In sum, psychological factors constitute neither necessary nor sufficient explanations for entrepreneurship or for entrepreneurial performance. Effectuation suggests new ways of interpreting these (non)results of psychological variables. Chapters 4, 5, 6 and 9 unpack and elaborate upon these.

The above effectual challenge to the explanatory power of psychological variables in entrepreneurship is consistent with entrepreneurship research that has extended a similar challenge and urged a closer examination of the processes of new venture creation as inseparable from the personality of the entrepreneur (Gartner, 1988; Shane and Venkataraman, 2000).

\subsubsection{The Environment and Evolutionary Processes}

For evolutionary theorists, the personality of the entrepreneur is neither necessary nor sufficient; it is in fact, often, simply irrelevant. What matters is that entrepreneurs create variations. These variations are then subject to selection processes that determine what survives and what does not. There are at least two distinct schools of evolutionary theorists - population ecologists with roots in sociological traditions and economists who are heavily invested in notions of competitive dynamics.

\section{Population ecology}

Aldrich (1999) exemplifies this tradition and integrates results from this perspective with entrepreneurship research. Aldrich draws upon the literature on competence-enhancing and competence-destroying innovations (Schmookler, 
1962; Utterback and Abernathy, 1975; Tushman and Anderson, 1986) to posit a continuum of entrepreneurial organizations ranging between reproducers and innovators:

The continuum from reproducer to innovator is defined by outcomes, not intentions (Aldrich and Kenworthy, 1999). Some entrepreneurs deliberately intend to depart from existing knowledge, whereas others give it no thought. Irrespective of intentions, individuals face a tension between deviating from existing routines and competencies and conforming to them. As Campbell (1982) noted, playfulness and experimentation are natural human impulses that have extraordinary strength and persistence, enabling people to generate variations of great utility. However, people's tendencies to defer to the beliefs of others partially offset the full expression of these strengths. (Aldrich, 2001: 80)

After discursive examinations of a variety of topics related to this view of organizational evolution, Aldrich identifies several under-researched areas and theoretical puzzles that suggest specific questions and hypotheses for analyzing and explaining phenomena such as SpaceShipOne. Some of these, such as the arguments I develop later about the positive role of advice, as opposed to Aldrich's negative connotation above, speak directly to the micro-foundations being developed in this book. For example, arguing that 'entrepreneurial knowledge ultimately derives from a mix of individual experience, connections within networks, learning from others, and blind variation', Aldrich (2001: 333) raises the puzzle about how entrepreneurs transform this knowledge into competence-destroying organizational innovations: 'Under what conditions does imitation and borrowing become creativity and innovation?' In the case of SpaceShipOne, this might translate to an examination of how Rutan moved from the design of research aircraft in and for government bureaucracies to designing a privately funded and affordable spaceship carrier.

Another relevant puzzle Aldrich raises has to do with collective action: 'We need to study the process by which organized action by clusters of actors contributes to the development of new organizations, populations, and communities' (Aldrich, 2001: 332). Here the relevance to the SpaceShipOne story is rather obvious - a set of disparate individuals, almost maverick participants, had to come together to make SpaceShipOne fly. Currently, there is very little theoretical light to be shed on how such a network of stakeholders comes to be.

Finally, in a recent article, Aldrich and Ruef (2018) point to the wrongheaded emphasis in entrepreneurship research on unicorns (ventures with a value of at least one billion dollars) and gazelles (fast growing companies that have increased their revenues by at least 20 percent per annum over four years) that leads to ignoring the vast and important population of ordinary entrepreneurs (Baker and Welter, 2014; Welter et al., 2015). 
Effectual logic seeks to shed light on all of these issues: (a) micro-mechanisms that help transform who the entrepreneur is, what she knows and whom she knows into new ventures and markets; (b) micro-processes that help founding entrepreneurs create new networks of self-selected stakeholders; and (c) how ordinary people can use these mechanisms and processes to build a wide variety of ventures, not only unicorns or gazelles that are most likely black swans (Taleb, 2007; Aldrich and Ruef, 2018). Chapter 5 is devoted to explicating these in some detail.

\section{Competitive dynamics}

There is a long tradition in economics of viewing entrepreneurship as a balancing act within the larger drama of competitive dynamics. Schumpeter (1975 [1942]), for example, posited the entrepreneur as the source of disequilibrium in the economy; Kirzner (1979) argued for entrepreneurial alertness as the trigger to the market processes that bring the economy back to equilibrium from disequilibrium; and there are a variety of shades in between including Baumol's (1993) spectrum of productive, unproductive, and destructive entrepreneurship.

Each of these views, however, makes certain assumptions about individual decision behavior and the conditions under which decisions are made (Evans and Jovanovic, 1989; Minniti et al., 2019). In particular, they assume that the future, albeit unknown, is predictable to a greater or lesser degree; that decision makers know what they want - i.e. their preferences are given and well-ordered; and that the environment is mostly exogenous to the individual's actions. Effectuation, as we will see later, goes to work in spaces where these assumptions do not hold. In other words, it helps push the basic economic world-view about individuals, firms and markets beyond its current frontiers. For example, in the case of SpaceShipOne, it is not clear what would count as a market, let alone what would be identifiable as equilibrium or disequilibrium in such a market.

Trying to understand the SpaceShipOne story through the competitive dynamics lens requires us to deal with slippery phenomena such as nascent markets, latent demand, technology trajectories and so on. It is not clear even now that there is actual demand or viable supply to sustain a space tourism industry or whether there ever will be. What existed at the time Rutan began developing SpaceShipOne can best be characterized as a technological frontier dominated by a bureaucratic monopoly, the National Aeronautics and Space Administration (NASA). Only time will tell whether SpaceShipOne is the beginning of a new gale of creative destruction or whether Burt Rutan is an alert entrepreneur who spotted a great disequilibrium. Will this story end in productive gains to the economy or destroy civilization as we know it? 
In the meanwhile, the actors in the drama continue to act, without knowing when and how the curtain might come down, or even what the next act will turn out to be. Their actions, as Shackle (1966) would argue, are not based on data, but mostly on figments. Effectuation explicates how and on what basis they act; and in what way that basis is consistent with or contrary to assumptions about human action in major economic theories. In particular, it begins to address questions that Dosi (1997) posed after reviewing empirical results from industrial organization as well as micro-, macro-, and evolutionary economics:

One of the points that I have tried to argue is that an interpretation of technological dynamics which significantly relaxes the commitments to equilibrium, rationality, and inter-agent homogeneity is straight-forwardly borne by the current evidence, and is also beginning to generate formalised theoretical tales - with implications well beyond technological change itself, addressing basic issues like how the future is linked to the past, how individual (possibly mistake[s]-ridden) decisions aggregate into collective outcomes, and how problem-solving knowledge is accumulated in society. (Dosi, 1997: 1544-5)

Dosi's sentiments were more recently echoed and reinforced in Winter (2016: 19):

Today, the main problem is not that entrepreneurship research is impoverished by weak support from economic theory, but that economics is impoverished by weak assimilation of the implications of entrepreneurship.

Effectuation offers micro-foundations for enriching economics in a variety of ways, a task that I outline and wade into in Chapter 9. Additionally, effectuation also begins to add micro-foundations to competitive dynamics issues in strategic management (see Chapter 8) and makes inroads into more recent theorizing in entrepreneurship that has begun putting entrepreneur (person) and market (opportunity) together in interesting ways. In particular, I will examine the work of Casson (2003) and Shane (2003). It is important to note that the latter directly builds on the seminal work of Venkataraman (1997).

\subsubsection{Putting Entrepreneur and Environment Together}

Mark Casson's theory of entrepreneurship takes its cue from Schumpeter, Knight and Hayek, each of whom identified the necessity for entrepreneurial 'judgment' in the face of extreme uncertainty (Foss and Klein, 2012). Their work brought to light the problem of partial knowledge (or the lack of it) in the entrepreneurial context. Each made important contributions to pushing forward mainstream economics beyond assumptions of perfect information and extant 
markets. Casson argues that this entrepreneurial 'judgment' is based on unique information that the entrepreneur exploits to create a 'market-making' firm. Casson's notion of 'market-making' goes beyond simple arbitrage and involves overcoming obstacles to trade that arise primarily due to ignorance (Casson, 2003). Thus Casson's entrepreneur specializes in the acquisition and processing of information that feed his good judgment and help him identify situations where competition from other entrepreneurs is relatively sparse. The market-making entrepreneur then proceeds to erect barriers to entry with a view to maximizing returns.

If we look at the story of SpaceShipOne through Casson's theory, Rutan's unique résumé will loom large in the explanatory equation. But it is not quite clear that Rutan and his team set out to maximize returns in any way. Nor is it even clear that they are in the process of 'market-making' in the specific sense in which Casson uses the term. Yet several of his conclusions, such as the role of previous experience and reputation in reducing the costs of market-making, the necessity of negotiation and other organizational skills etc., are relevant and valid in understanding the space tourism market-in-the-making. It is here that the ideas in this book matter. They look into the content of these skills that Casson identifies as necessary to the entrepreneurial function. A close examination of those contents reveals some aspects that are contrary to certain details in Casson's theory. For example, Casson preserves the essentially adversarial tone of most stakeholder negotiations. However, empirical work on effectuation shows that standard arguments from contract theory about threats of opportunism and moral hazards appear not to hold up well in how expert entrepreneurs actually build and exercise good judgment, and make new markets. Rather the tone and behavioral assumptions here are more in line with Adam Smith's observations in The Theory of Moral Sentiments (Smith, 1822).

Elements of entrepreneurial expertise identified in this book also overlap with and differ from Shane's theory about entrepreneurial opportunities. I am in complete agreement with Shane and Venkataraman (2000) that we need to look into the nexus of enterprising individuals and valuable opportunities if we are to understand entrepreneurship better. Furthermore, expert entrepreneurship finds common ground with Shane's interest in a means-ends framework as the key piece in the entrepreneurial puzzle. However, as it will become amply clear later in the book, there is a fundamental difference in the logical frame used by Shane's entrepreneur, who is engaged in the discovery and exploitation of opportunities, and the effectual entrepreneur, who ends up fabricating them from the mundane realities of her life and value system along with stakeholders who self-select into the process.

Even at the risk of oversimplification, a quick application of the two views to the case of SpaceShipOne might be useful here. Shane's theory suggests that Rutan saw the profit opportunity in space tourism and therefore undertook the 
development of SpaceShipOne. The ideas in this book suggest that the market opportunity for space tourism (and any profits it may or may not entail) ensued from what Rutan and his stakeholders did. Their actions in turn sprung from the inter-subjective interactions between Rutan (with his love of and skills for designing aircraft), Allen (with his passion for the exploration of space), and a variety of stakeholders, each of whom self-selected into the venture by committing what $\mathrm{s} / \mathrm{he}$ could afford to lose without worrying about positive cash flows down the road.

In addition to connections with the above literature streams, effectuation also coheres with several streams of work that are beginning to coalesce with entrepreneurship research. Let us consider a few examples. One area that was always central to entrepreneurship but is now beginning to inspire and challenge management scholars and economists is Knightian uncertainty. Consider, for example, the 2020 special issue of Academy of Management Review on this (Alvarez et al., 2018) or several other publications reviewed in Townsend et al. (2018). Additionally, in his editorial outlining a vision for future research in entrepreneurship, Shepherd (2015) emphasizes several themes that are directly flowing from and overlapping with effectuation research. Examples include a more interactive perspective of opportunity, entrepreneurship that is more activity based, and a richer view of motivations such as prosocial ones. Finally, as the literature on networks continues to grow and deepen, it has begun tackling the dynamics of how networks form and develop (Ahuja et al., 2012). This rising stream definitely offers a lot of promise for profitable dialog with effectuation research (Slotte-Kock and Coviello, 2010; Kerr and Coviello, 2019, 2020). All of these connecting streams can help unpack rich entrepreneurial phenomena such as SpaceShipOne. Even though at first glance it may appear to be a spectacular instance, it actually raises a variety of issues of great interest to all of entrepreneurship, splendid and mundane. Each of these issues has to do with unspecified micro-foundational mechanisms that make theories of entrepreneurship work. In my view, these mechanisms comprise the elements of entrepreneurial expertise. And my objective in this book is to identify these elements and relate them in rigorous detail to the making of entrepreneurial ventures across multiple contexts and over time.

\subsection{ENTREPRENEURSHIP AS A DOMAIN OF EXPERTISE}

In sum, one can argue that entrepreneurial performance has traditionally been studied either (1) as a set of personality traits of the entrepreneur that explains the success or failure of the firms he or she creates (Llewellyn and Wilson, 2003), or (2) as a set of circumstances or attributes of the project and its environment that contains the seeds of its success or failure (Thornton, 
1999). In the former case, potential entrepreneurs either have the right traits, or they don't. And if they don't, entrepreneurs are urged to cultivate them. In the latter, potential entrepreneurs are called on to develop strategies and skills for recognizing, identifying and exploiting high potential opportunities within existing contexts.

I intend to come at the subject from a different angle by focusing on entrepreneurial expertise (Mitchell, 1994). Expertise consists in tacit as well as learnable and teachable aspects of experience that are related to high performance in specific domains. Instead of taking either traits or circumstances as inputs and trying to explain variance in performance, the expertise lens focuses on understanding commonalties across a variety of experts in a single domain, given high levels of performance. In keeping with the literature, I define an expert as 'someone who has attained a high level of performance in the domain as a result of years of experience' (Foley and Hart, 1992) and deliberate practice (Ericsson et al., 1993). The question of whether deliberate practice is feasible in entrepreneurship (Baron, 2009) and what could form a basic unit of deliberate practice leading to effectual entrepreneurial expertise (Dew et al., 2018a) will be elaborated in some detail in Chapter 11 .

\subsubsection{Key Empirical Questions}

I started my empirical work by asking the following question:

What commonalties and differences exist in the decision-making processes of a group of expert entrepreneurs who start with the same idea for a new venture and face exactly the same set of decisions in building it?

Because all decisions in an entrepreneurial setting pertain either to future markets, or to markets for future goods and services (Venkataraman, 1997), they involve risks and uncertainties of various kinds. Also, human beings vary in their beliefs about the predictability of the future (Kahneman et al., 1982). This led me to the second question:

In the face of non-existent or not-yet-existent markets, what underlying beliefs about the predictability of the future influence the decisions expert entrepreneurs make as they build a new venture?

One of the simplest ways to find out what expert entrepreneurs have learned from their experience is to ask them. Interviews of entrepreneurs and their stakeholders, triangulated with published data, can and do form the basis of valid studies with interesting results (Smith and Miner, 1983; Hartwell and Torbert, 1999; Sexton, 2001). But expert entrepreneurs are usually good 
storytellers (Lounsbury and Glynn, 2001). Therefore, studies based on their stories after the fact may be subject to retrospective bias. To get around this bias, I used think-aloud verbal protocols. In this method, subjects in the study are given a set of typical problems from their domain of expertise and asked to think aloud continuously as they solve the problems.

The essential logic behind the use of protocol analysis can be summarized as follows: while retrospective recall allows subjects to make up good stories about how they believe they solve problems, and stimulus-response methods force researchers to deduce the subjects' decision-making processes after the fact, concurrent verbalization allows the researcher to look directly inside the black box of cognitive processing, because of the structure of the brain's short term memory system. As Ericsson and Simon put it:

There is a dramatic increase in the amount of behavior that can be observed when a subject is performing a task while thinking aloud compared to the same subject working under silent conditions. (Ericsson and Simon, 1993)

\subsubsection{Studying Entrepreneurial Expertise}

I had the good fortune to work with Herbert Simon during the last six years of his life. He, along with his colleagues, led the field of cognitive science in investigations of expertise over 30 years ago. The earliest studies had to do with chess grand masters (Chase and Simon, 1973). In their early study of expert chess players, Chase and Simon (1973) observed that simple intelligence had no correlation with chess mastery, a finding later confirmed more generally by others (Taylor, 1975; Ceci and Liker, 1986; Doll and Mayr, 1987).

Instead, the grand masters' expertise had to do with other factors such as, how players stored information, perceived problems and generated solutions. Building on the foundation laid by Simon and his colleagues, the field of expertise studies began to expand. While some of the early empirical literature and theory development focused on chess, subsequent work has validated and expanded the theoretical base to include more dynamic settings where rules are not as well defined and outcomes are linked with several complex tasks over time. Examples include taxi-driving (Kalakoski and Saariluoma, 2001), medicine (Boshuizen and Schmidt, 1992), music composition (Krampe and Ericsson, 1996), fire-fighting (Hoc and Moulin, 1994), consumer decision-making (Selnes, 1989), and scientific discovery (Klahr and Simon, 2001). It is important to note that the majority of findings in less dynamic settings are robust to more dynamic settings as well.

A detailed review of the expert-novice literature would take up more shelf-space than I want to devote to the topic here. Fortunately, there are two excellent handbooks on the subject that cover hundreds of studies from dozens 
of domains (Ericsson et al., 2006; Ericsson et al., 2018). What makes the study of any particular domain of expertise interesting is that the elements of expertise may be organized into a set of domain-specific heuristic principles, which can thereafter be either embodied in expert systems or used as testable and teachable decision-making and problem-solving techniques. Studying entrepreneurship as a form of expertise not only allows us to develop such techniques for entrepreneurship, but also introduces an important new perspective to the field that especially impacts current views about entrepreneurial performance.

\subsubsection{Performance of the Entrepreneur, not just of the Firm}

Current studies of entrepreneurship tend to focus on the performance of the entrepreneurial venture as the primary dependent variable (Angus, 2019). Even the literature on traits, knowledge acquisition (tacit and otherwise), learning, and the use of general (non-domain-specific) heuristics and biases all seek to explain how these factors influence the performance of the firms that entrepreneurs create. The view from entrepreneurial expertise, however, turns the spotlight on the performance of the entrepreneur, sometimes in harmony with, but at other times in opposition to, the performance of the firm. Entrepreneurs, in current scholarship, are seen as instruments in the birth and growth of firms. Entrepreneurial expertise proposes an instrumental view of the firm instead (Dew et al., 2008).

Studies of expertise suggest that although expertise often overlaps with and explains success, expertise is not the same as success (Gardner, 1995; VanLehn, 1996). The fact that a chess player wins a tournament does not automatically imply he or she is a grand master or even a run-of-the-mill expert; similarly, being an expert chess player does not guarantee a win. This is even more applicable to entrepreneurial expertise. An expert entrepreneur may found one or more failed firms; and novice entrepreneurs may achieve supra-normal profits in their very first ventures.

This suggests that by equating entrepreneurial performance exclusively with firm performance, we are overlooking an important avenue through which expert entrepreneurs achieve success, namely through failure management. Sustained performance over long periods of time requires that experts outlive failures, cumulate successes, and learn from both. Therefore, the content of entrepreneurship ought to include the separation of firm performance from the performance of the entrepreneur. This separation also implies that studying expertise in complex domains involves defining experts using criteria beyond success and failure. Chapter 6 explores some of the subtleties involved in the relationships between entrepreneurial expertise and the performance of firms and entrepreneurs. 
I will describe my research design in detail and present the methods of analyses in the next chapter. Here, I end this chapter with a brief summary of results to be developed through the rest of the chapters in the book.

\subsection{SUMMARY OF FINDINGS: ELEMENTS OF ENTREPRENEURIAL EXPERTISE}

The following is a brief summary of the findings from the original protocol analysis study and subsequent theoretical developments. The summary is divided into three parts.

\subsubsection{Process Elements of Entrepreneurial Expertise}

- Although the process can begin anywhere including accidental encounters with problems or the urging by interested stakeholders other than the entrepreneur, or even sheer routine, expert entrepreneurs usually begin with who they are, what they know and whom they know.

- They focus on what they can do for affordable loss and do it, without worrying much about what they ought to do.

- Some of the people they interact with self-select into the process by making commitments to the venture.

- Each commitment results in new means and new goals for the venture.

- As resources accumulate in the growing network, constraints begin to accrete. The constraints reduce possible changes in future goals and restrict who may or may not be admitted into the stakeholder network.

- Assuming the stakeholder accumulation process does not prematurely abort, goals and network concurrently converge into new artifacts such as firms, markets and institutions.

The process is graphically represented in Figure 5.1 and explicated in greater detail in Chapter 5. Since the process model has been modified and extended in a variety of ways in recent research, I will outline several of these in Chapter 11 .

\subsubsection{Principles of Entrepreneurial Expertise}

At each step of the process, expert entrepreneurs use the following principles. Each principle inverts key decision-making criteria in received theories and conventional management practices. 


\section{The bird-in-hand principle}

This is a principle of means-driven (as opposed to goal-driven) action. The emphasis here is on creating something new with existing means rather than discovering new ways to achieve given goals.

\section{The affordable loss principle}

This principle prescribes committing in advance to what one is willing to lose rather than investing in calculations about expected returns to the project.

\section{The crazy quilt principle or (alternatively, the self-selection principle)}

This principle involves negotiating with any and all stakeholders who are willing to make actual commitments to the project, without worrying about opportunity costs, or carrying out elaborate competitive analyses or targeting specific resource providers.

Furthermore, who comes on board determines the goals of the enterprise. Not vice versa.

\section{The lemonade principle}

This principle suggests acknowledging and appropriating contingency by leveraging surprises rather than trying to avoid them, overcome them, or adapt to them.

\section{The pilot-in-the-plane principle (alternatively, the co-creation principle)}

This principle emphasizes the worldview that history does not run on auto-pilot, but is co-created through human action. It brings into sharp focus the need to treat all stakeholders as co-pilots. There are no passengers on the effectual journey.

Each of the five principles above embodies techniques of non-predictive control - i.e. reducing the use of predictive strategies to control uncertain situations. Together, these principles point to a logic of action called effectuation.

Effectuation is the inverse of causation. Causal models begin with an effect to be created. They seek either to select between means to achieve those effects or to create new means to achieve pre-selected ends. Effectual models, in contrast, begin with given means and seek to create new ends using non-predictive strategies. In addition to altering conventional relationships between means and ends and between prediction and control, effectuation rearranges many other traditional relationships such as those between organism and environment, parts and whole, subjective and objective, individual and social, and so on. In particular, it makes these relationships a matter of design rather than one of decision. 
Empirically, entrepreneurs use both causal and effectual approaches, in a variety of combinations. Use of and preference for particular modes is related to the entrepreneur's level of expertise and where the firm is in its life-cycle. Theoretically, however, it makes sense to analyze causal and effectual approaches as a strict dichotomy.

Note: The point about the rich and complex texture of empirical reality and the stark simplicity of theoretical dichotomies is worth belaboring. The Argentine writer Jorge Luis Borges once wrote about mapmakers who became so obsessed with correspondence to reality that their map became larger and larger until it was congruent with the city. Such a map, of course, is utterly useless. I propose the logic of effectuation as one among many useful maps to the same city. It is not a negation of alternate logics such as those underlying subjective expected utility models of economics, resource-dependent models of social movements, or opportunity recognition models of entrepreneurship. My only claim (that I work hard to establish through this book) is that effectuation has its particular and unmatched uses in current theorizing about entrepreneurial (micro) behavior that lies at the heart of many economic theories and social philosophy.

\subsubsection{Effectuation: The Logic of Entrepreneurial Expertise}

By logic, I mean an internally consistent set of ideas that forms a clear basis for action upon the world. A causal logic is based on the premise: 'To the extent we can predict the future, we can control it.' An effectual logic is based on the premise: 'To the extent we can control the future, we do not need to predict it.'

The use of an effectual logic implies a certain stance toward the world and its occupants. In particular:

- Effectuators see the world as open, still in-the-making. They see a genuine role for human action. In fact, they see both firms and markets as human-made artifacts. In this sense, effectual entrepreneurship is not a social science. It is a science of the artificial. (Simon, 1996; Sarasvathy, 2003)

- Effectuators very rarely see opportunities as given or outside of their control. For the most part, they work to fabricate, as well as recognize and discover opportunities. (Sarasvathy et al., 2003)

- Effectuators often have an instrumental view of firms and markets. They do not act as though they were the agents of the firm or as suppliers catering to demand - firms are a way for them to create valuable novelty for themselves and/or for the world; markets are more likely made than found; 
and a variety of stakeholders including customers are partners in an adventure of their own making. (Sarasvathy et al., 2020)

- Effectuators do not seek to avoid failure; they seek to make success happen. This entails a recognition that failing is an integral part of venturing well. Through their willingness to fail, effectuators create temporal portfolios of ventures whose successes and failures they manage - learning to outlive failures by keeping them small and killing them young, and cumulating successes through continual leveraging and working with self-selected stakeholders. In an effectual universe, success/failure is not a Boolean variable and the success/failure of the entrepreneur does not equal the success/ failure of the firm. (Sarasvathy et al., 2013)

Effectuation matters, not merely because expert entrepreneurs prefer an effectual logic over a causal one, but because of the details it offers of a comprehensive alternate frame for tackling entrepreneurial problems. Which frame entrepreneurs use influences how they formulate problems; what alternatives they perceive and generate; which constraints they accept, reject, and/or manipulate and how; and why they heed certain criteria rather than others in fabricating and implementing new solutions. Logical framing matters because it makes a real difference in the world and makes a world of difference in the reality entrepreneurs perceive and make possible or impossible.

In sum, effectual, as opposed to causal, framing is about redrawing the problem space and reconstituting extant realities into new opportunities.

\section{NOTE}

1. I have put together the story from dozens of published reports. 